\title{
THREE UNUSUAL CASES OF SPINAL CORD INJURY IN CHILDHOOD
}

\author{
By M. Renard, ${ }^{1}$ P. Tridon, ${ }^{1}$ M. Kuhnast, ${ }^{1}$ J. M. Renauld, ${ }^{1}$ and P. Dollfus ${ }^{2}$ \\ ${ }^{1}$ Nancy, ${ }^{2}$ Mulhouse, France
}

\begin{abstract}
Three cases of unusual traumatic spinal cord injuries are reported. The cases were referred to the neurosurgical unit of Nancy, one tetraplegia and one paraplegia caused by transfixing wounds which were overlooked after the injury. The transfixing wound caused an associated meningitis with tetraplegia, and in the second case the initial small plural effusion associated with paraplegia even, in a very short while, evoked a possible diagnosis of leukaemia amongst others, until the knowledge of trauma had been ascertained, the child being then immediately transferred to the neurosurgical unit. Spanking, in the last case, was the cause of an important luxation of TI2-LI, at first with a complete paraplegia, and was associated with the fact that the child was only seen a few days after by a doctor and immediately referred. The child made a full recovery from his paraplegia.
\end{abstract}

Key words: Spinal cord injury; Children

\section{Introduction}

THE list of cases concerning traumatic injuries to the spinal cord during childhood is relatively small although some scattered cases are still unpublished.

We would like to add three cases to this list mainly because of the unusual aetiology, diagnostic and therapeutic problems encountered.

\section{Case Reports}

Case No. I. Christian de A., 8 years old, boy, admitted to the neurosurgical unit with an incomplete tetraplegia appearing 24 hours after a fall, apparently without consequences, upon an agricultural hay-raking machine. On admission, the diagnosis of a spinal cord syndrome, motor complete below $\mathrm{C}_{5}$, complete sensory below Ti. All the reflexes were absent, except the bicapital reflex which was present on the left side. $\mathrm{He}$ also had a high temperature of $39.5^{\circ} \mathrm{C}$ and meningitis symptoms. A lipiodol myelography was performed showing a slowing of the index in front of $\mathrm{C}_{4}-\mathrm{C}_{5}$ evoking, first of all, an extradural haematoma in relation with the interval between the accident and the neurological involvement. The lumbar puncture showed that the C.S.F. was pink, cloudy and there was a complete manometric block. More careful examination of the myelogram pictures showed a small image of escape of the lipiodol outside the dura (Fig. I). Very close examination of the skin prior to operation disclosed a parasagittal $3 \mathrm{~mm}$ small rounded wound approximately $5 \mathrm{~cm}$ on the left side of the median line at the level of $\mathrm{C}_{4}-\mathrm{C}_{5}$. During the intervention a fracture of the lamina of $\mathrm{C}_{4}$ was noticed, the lamina being itself perforated and projected into the vertebral canal (Fig. 2). A compressive epidural hydroma was evacuated after laminectomy of $\mathrm{C}_{3}-\mathrm{C}_{4}-\mathrm{C}_{5}$ and a small breach situated posteriorly and laterally on the left side of the dura was also found. The opened dura showed the macroscopic integrity of the spinal cord. The next morning the child was transferred to a medical ward for treatment of signs of a severe meningitis

Address for offprints: Monsieur le Professeur Michel Renard, I Place Aimé Morot, 54000 Nancy, France. 


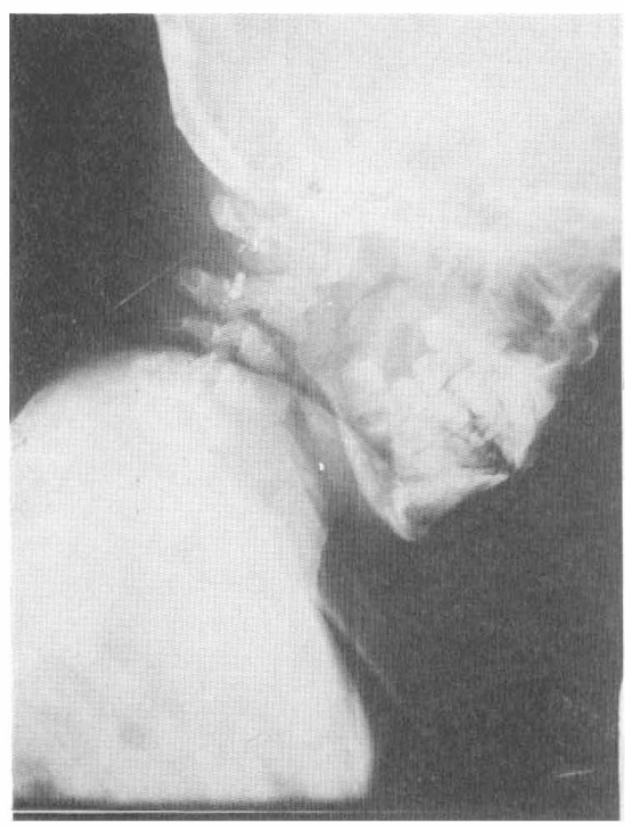

FIG. I

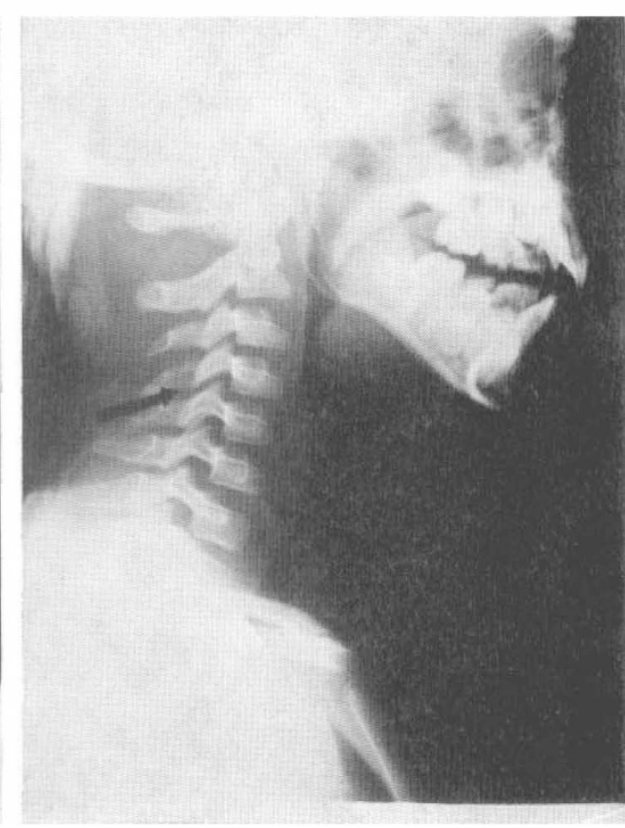

FIG. 2

Fracture at $\mathrm{C}_{4}$.

which lasted for 2 weeks. The mechanism of the tetraplegia was that of a transfixion wound by one of the metal spokes of the rake; this had remained unknown. Neurologically there was a gradual return of sensation overall as well as some motor power in the upper and lower limbs but no return of triceps movements. The return of motor power is still hindered by a severe spasticity mainly in the lower limbs. $\mathrm{He}$ is independent in a wheelchair. He can walk in parallel bars. His automatic bladder function is satisfactory.

Case No. 2. Francis D., I I years old, boy, was admitted into a local hospital (1974) after a fall from his own height on his back on to an iron spoke embedded in concrete. After the fall he had a complete flaccid paraplegia below $\mathrm{T}_{3}$, the relationship between the two was ascertained only after. The examination of the skin in the back only showed a minimal wound on the lateral side of the right hemithorax just under the scapula which was stitched. There was no apparent bony injury on the chest X-rays which showed a small right-sided hemi-pneumothorax. The lumbar puncture: clear C.S.F., no manometric block. Three days later he was transferred to the neurosurgical unit from the local hospital. A lipiodol myelogram demonstrated a meningeal fistula (Fig. 3) in front of T2 with a passage of the contrast fluid into the mediastinum. The hemithorax was aspirated again and $200 \mathrm{ml}$ of blood was removed. A laminectomy of $\mathrm{T}_{2}-\mathrm{T}_{3}-\mathrm{T}_{4}$ was performed, two breaches were seen, one situated laterally in front of $\mathrm{T}_{2}$ and another posteriorly in front of $\mathrm{T}_{1}$ and $\mathrm{T}_{2}$ (Fig. 4). In this last breach a small piece of the body of T2 was found which transfixed the spinal cord destroying the antero-lateral and posterior funiculi and the right lateral side of the grey matter. The surgical exploration of the thorax showed a transversal wound in the sixth intercostal space situated at the level of the posterior axial line. At the level of the muscles the lesion was found to be oblique towards the front and upwards explaining the penetration of the pleura between the fifth and sixth costae. The mechanism of the paraplegia was explained by the fact the metal spoke had, in fact, transfixed the thorax causing 


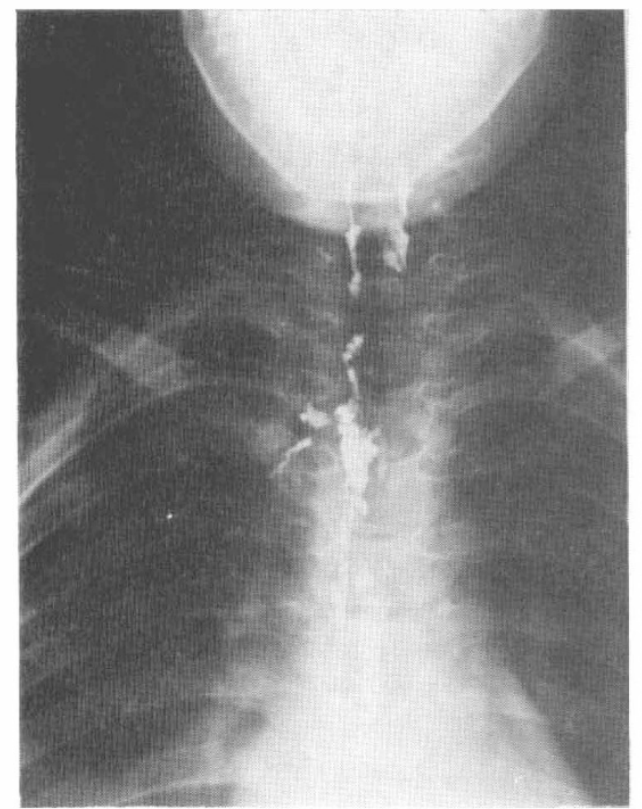

FIG. 3

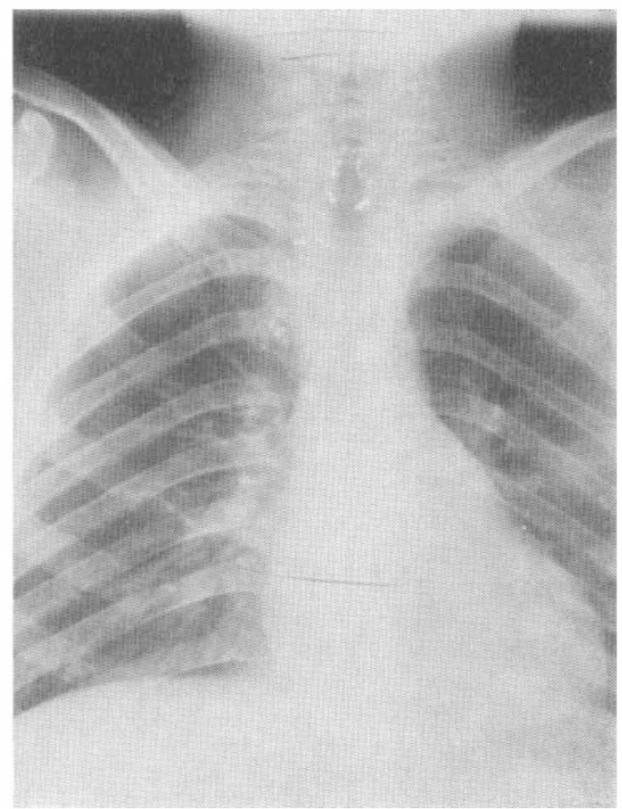

FIG. 4

The clip on the left side shows the posterolateral breach. Two clips show the penetration of the dura and the antero-lateral penetration of the bony fragment.

the hemi-pneumothorax tearing off a bony fragment of $\mathrm{T} 2$ and pushing it backwards and upwards causing the spinal cord lesion. After the operation he was transferred to a respiratory resuscitation unit for 6 weeks. Neurological evolution: the sensory and motor level had descended to $\mathrm{T}_{9}$ with a presence of the dorsal and abdominal wall muscles corresponding to the segmental level but one noticed that there was no intercostal activity below $\mathrm{T}_{4}$. Rehabilitation, here, was otherwise uneventful apart from a moderate spasticity, a small scoliosis and a good automatic function of the bladder.

Case No. 3. Fabrice Sch., I3 months old, boy, sent to the neurosurgical unit in I975 with the diagnosis of a luxation of $T_{12}$ behind $L_{1}$ and a complete flaccid paraplegia below Ti2. The anamnesis, here, is rather vague and confused. The child was kept at home by an alcoholic parent and had been submitted to a forceful spanking some days before... ! The mother, in fact, 'noticed' the paralysis of both the lower limbs and an important cyphosis, this for a few days before the child was sent to the unit. It must be noticed that the child had also had a purulent meningitis at the age of 6 weeks and was mentally retarded. On admission the diagnosis of a complete flaccid paraplegia below TI 2 was confirmed as well as a urinary retention and paralytic ileus. The X-ray of the spine showed an important posterior luxation of TI2 (Fig. 5), thus creating the 'noticed' cyphosis. An open reduction was then performed, with the help of longitudinal manual traction but appeared to be very unstable. On inspection the conus was flattened with a thickness of approximately $5 \mathrm{~mm}$ but otherwise there was no presence of macroscopic evidence of contusion. The luxation was stabilised and fixed by wiring, although not completely reduced (Fig. 6). Next morning sensation for pain reappeared as well as some motor function in the toes. Two weeks later there was a very good recovery of the motor power in the lower limbs except in the left foot. An E.M.G. control two months later showed a peripheral involvement of $\mathrm{L}_{4}-\mathrm{L}_{5}$ and $\mathrm{S}_{\mathrm{I}}$ on the left side and $\mathrm{SI}_{\mathrm{I}}$ 


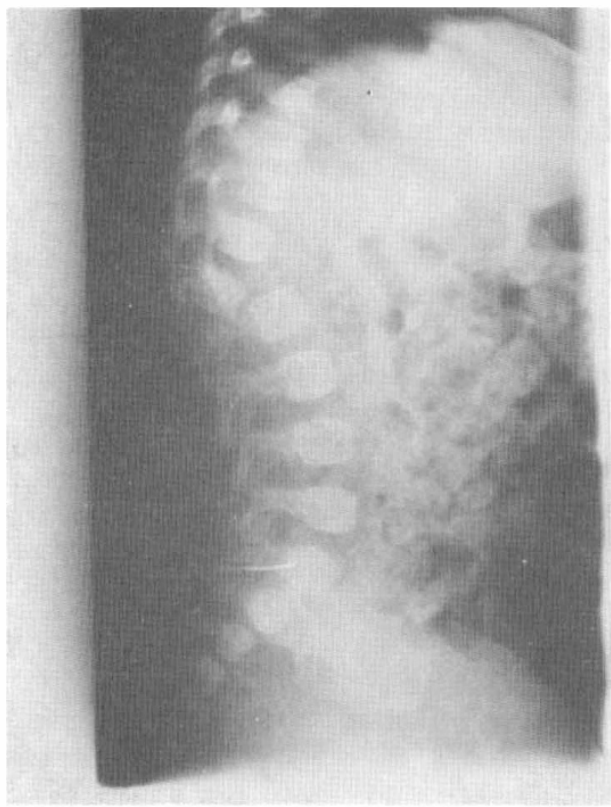

FIG. 5

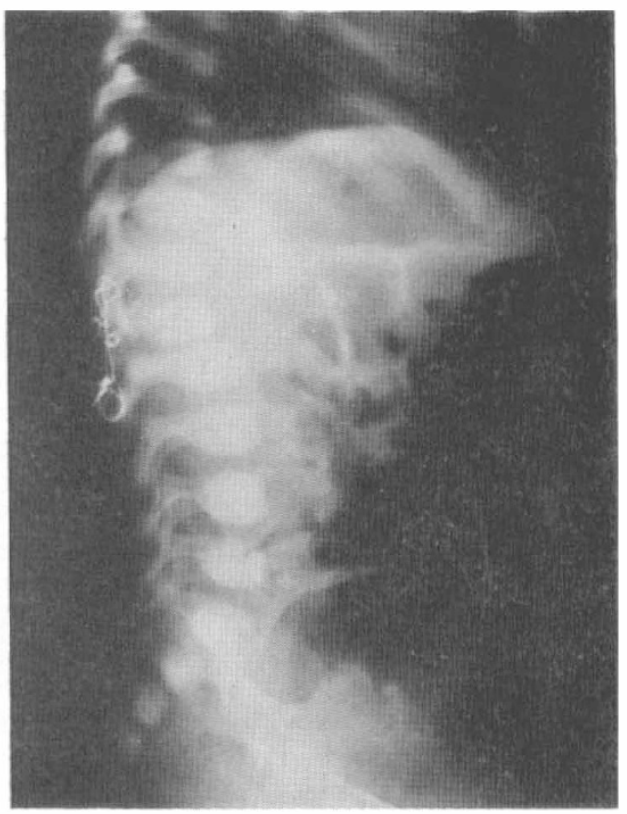

FIG. 6

on the right side. Fifteen months later the child was seen and one could say there was a complete recovery, but because of the meningitis, the child remains mentally handicapped. Seen very recently again, there was no neurological sequelae of the paraplegia and no vertebral growth problem.

\section{Discussion}

In the first case (tetraplegia) the aetiology was, at first, that of meningitis, which, in fact, did exist, as the presence of the causal transfixing trauma was, in the first instances, overlooked. The skin wound was extremely small, barring a point covered by a small crust.

In the second case the transfixing wound had already been stitched. In the absence of knowledge of trauma, the possible diagnosis of leukaemia was even postulated. When the presence of trauma was ascertained the child was immediately transferred for neurosurgical advice.

As for the case of excessive spanking the true anamnesis, for social reasons, was very difficult to obtain and on admission the notion of trauma was obvious.

Not only literature referring to trauma and spinal cord injuries during childhood is very scarce; it has been lately reviewed by Burke (I97I, I974), Cheshire (1976) and Hachen (1976). It was impossible to find a case where the transfixing agent, as the causal mechanism, had passed unnoticed. One case of battering has been mentioned by Hancock during the discussion of Burke's paper in I97I.

\section{SUMMARY}

We thought worth while bringing forth three unusual cases of spinal cord injuries demonstrating the capital value of an anamnesis very difficult to obtain, especially in the case of children. 


\section{RÉSUMÉ}

Trois cas de lésions médullaires inhabituelles chez l'enfant sont décrits; deux cas par transfixion méconnue au début et un autre cas avec une luxation dorso-lombaire importante par violence corporelle.

\section{ZUSAMMENFASSUNG}

Es wurden drei Fälle Querschnittlsäsionen beim Kind erwähnt: zwei durch nicht bemerkte offene Wunden und der dritte mit einer grossen dorso-lumbalen Luxation durch köperliche Bestraffung.

\section{REFERENCES}

Burke, D. C. (I97I). Spinal trauma in children, Paraplegia, 9, I-I2.

Burke, D. C. (I974). Traumatic spinal paralysis in children, Paraplegia, II, 268-276.

Cheshire, D. J. E. (1977). The paediatric syndrome of traumatic myelopathy without demonstrable injury, Paraplegia, 15, 74-85.

HACHEN, H. J. (1977). Spinal injury in children and adolescents: diagnostic pitfalls and therapeutic considerations in the acute stage, Paraplegia, 15, 55-64.

\section{Announcement}

The Third Congress of the International Rehabilitation Medicine Association will take place from the 2nd to 7 th July 1978 in Basle, Switzerland. Applications to be sent to the President's Secretariat: Medical Department, CH-73Io Bad Ragaz. Telephone 0859 I906. This Congress will be of interest to many members of the Society. 